\title{
The Role of the Addressee and Gender Diversity in Greeting Behavior in the Saudi Context
}

\author{
Huda A. Almushayqih ${ }^{1,2}$ \\ ${ }^{1}$ Department of English Language and Translation, College of Arabic and Social Science, Qassim University, \\ Qassim, Saudi Arabia \\ ${ }^{2}$ Department of English Language and Translation, College of Science and Art in Alassyah, Qassim University, \\ Qassim, Saudi Arabia \\ Correspondence: Huda A. Almushayqih, College of Science and Art in Alassyah, Qassim University, Qassim, \\ Saudi Arabia.
}

Received: April 20, 2020

Accepted: May 14, 2020

Online Published: May 15, 2020

doi: 10.5539/elt.v13n6p1

URL: https://doi.org/10.5539/elt.v13n6p1

\begin{abstract}
The current paper investigates verbal and nonverbal greeting behaviors in the Saudi context. The study aims to identify how Saudi males and females greet their parents, grandparents, siblings, and friends, and what role the addressee plays on the performance of the greeting behavior. The study further distinguishes the similarities and differences between Saudi males and females in their greeting behavior. This study is a mixed method study that adopts qualitative and quantitative methodologies. The participants of the study are 72 Saudi adults, 50 females and 22 males. The findings show that Saudis accommodate their greeting behavior according to their addressee's gender, age, social (familial) status, and social distance. Moreover, the findings revealed that males and females vary in the way they greet their relatives and friends. This variation is interpreted in the light of previous studies. This study provides some practical implications for the successful and meaningful greeting as well as successful interactions.
\end{abstract}

Keywords: females, greeting, greeting behavior, males, rituals, Saudi

\section{Introduction}

People around the world greet each other differently. Furthermore, males and females have different manners in greeting other people. This diversity sources from different cultures and perspectives around the world and could lead to miscommunication. In addition, the identity of the greeted individual may influence the greeter behavior.

A considerable number of researches have investigated the difference between males and females in performing speech acts. Yoosefvand and Rasekh (2014) argue that Iranian males and females express their gratitude differently. They, further, add that females are more likely to express gratitude than male. Greeting behavior as a speech act has been studied to describe the general greeting behavior of a certain community (Al-Shehri, 2008), or as across cultural study that compares greeting behavior of two different cultures (Almegren, 2017), or the difference between male and female in their greeting behavior (Al-Shehri, 2008).

Until recently, there have been few studies that investigate greeting behavior in the Saudi context. Furthermore, far too little attention has been paid to the role of the addressee in greeting rituals. According to the audience design theory, people modify their speech style according to their audience for different purposes. What is interesting here is how greeting rituals may be affected by audience design theory although greeting has the same purposes in different situations.

The exploration of human speech acts is the interest of many sociolinguists as it reveals social and cultural aspects of language. So, because greeting is the first step in interactions and it affects the further communication positively or negatively, it is significant to investigate the greeting behavior in each culture to develop positive interaction and avoid misunderstanding. Moreover, gender plays a role in the expression of speech acts as different genders have different roles in society.

In order to develop communication and meet peoples' expectations within the society, it is worthy of investigating the greeting behavior in the Saudi context and explore how people greet each other according to their gender and the addressee's identity. 


\subsection{Context of the Problem}

Greeting behavior is the interest of many sociolinguists around the world. A considerable number of researches have been conducted to reveal the greeting rituals of different communities (Al-Shehri, 2008; Medina et al., 2018). In the Saudi context, much of the studies have addressed the issue of greeting rituals in terms of gender differences (Al-Shehri, 2008). However, few studies in the Saudi context consider the influence of the addressee on Saudis' greeting behavior.

\subsection{Problem of the Study}

Although gender plays a role in the way people speak and behave, the identity of the addressee and how close or distinct the addressee is to the greeter may affect the greeter's behavior.

\subsection{Research Questions}

1. How do Saudi females / males greet their grandparents, parents, siblings, and friends?

2. What are the reasons behind each greeting behavior from males and females' perspectives?

3. How different are Saudi males and females in their greeting behaviors?

\subsection{Objectives of the Study}

The current research aims to:

1. Explore the greeting behaviors of Saudi males and females.

2. Investigate how Saudi males and females greet different people.

3. Seek information about the role of the addressee in males and females' greeting behavior.

4. Identify the reasons behind this diversity in greeting behavior considering both the greeter gender and the addressee's identity.

5. Describe the difference between male and female greeting behavior in general.

\subsection{Significance of the Study}

The present study is important for some reasons:

1. Greeting behavior is very significant and can affect the interaction between speakers since it is the first stage of any interaction.

2. Investigating greeting behavior in different cultures enhances successful interaction and reduces misunderstanding.

3. To develop communication and meet peoples' expectations within the society, as Saudi males and females have certain constraints on their interactions.

4. Analysis of greeting behavior provides information about interaction constraints among Saudi males and females.

5. It will reveal the social and cultural aspects of the Arabic language in the Saudi context.

\section{Review of Literature}

\subsection{Theoretical Background}

\subsubsection{Speech Act Theory}

People use different kinds of speech act in their daily communication, Meyerhoff (2006) describes speech act as utterances that introduce an activity like requesting, greeting, and thanking. Wardhaugh (2006) describes speech act as utterances "being used to do something, not just to say something" (p, 287), so they perform an action. In this sense, it can be argued that people use speech acts for different purposes, like apologizing and promising (Wardhaugh, 2006), they are "tactical moves" people employ when communicating with others to achieve their goals (Ball, 2010, p. 394).

Wardhaugh (2006) discusses two basic kinds of speech acts: Phatic utterances and Performative utterances. Phatic utterances don't represent information of fact, rather, they are considered as means for triggering interactions and opening conversation, like saying 'How do you do?' and 'Nice weather today' (Wardhaugh, 2006). Performative utterances are used not only to say something, but also to do an action (Wardhaugh, 2006). Greeting expressions can fall somewhere between Phatic and Performative utterances, they can be use to trigger interaction or to perform an action of salutation. However, Austin (1962) refers to some felicity conditions that must be available for purposeful use of Performative utterances, which are (i) having a conventional act for that 
behavior, (ii) all participants must fairly and completely perform that act, and (iii) participants must share certain required feelings, thoughts, and intentions when performing that act.

However, Holmes (2013) argues that speech acts can be performed and interpreted differently in different communities. She indicates that each speech act utterance entails a cultural and social function. Austin (1962) categorizes Performative utterances into five categories: verdictives (giving of grade or appraisal), exercitives (practicing power), commissives (by which a commitment is made), behabitives (by which an attitude is adopted), and expositives (by which an explanation is made). Nevertheless, what is considered as verdictives or exercitives in one culture is not necessarily considered the same in another culture, as Wardhaugh (2006) argues that different cultures have different forms of performativity. To this point, speakers need to be careful when communicating with different cultures or societies.

\subsubsection{Gender and Language Variation}

No one can deny that men and women are two distinct creatures, they can be distinguished biologically and linguistically (Wardhaugh, 2006). In the field of sociolinguistics, traditional variationists consider gender as a global variable of language variation as well as age, class, and ethnicity (Baxter, 2011). Almost in all speech communities, different genders use language differently (Holmes, 2013). The distinction between male and female use of language can be realized through a number of linguistic features, such as pronunciation, word-shapes, pronouns and so on (Holmes, 2013; Wardhaugh, 2006). Even on the morphological level, the two genders vary in their vocabulary choices (Wardhaugh, 2006). Lackoff (1973) mentions that women tend to use certain vocabulary which are not preferred to men. Some languages provide linguistic patterns that are used be certain gender, which means language can refer to the interlocutors' gender, the speaker and the one is being talked to (Wardhaugh, 2006).

Baxter (2011) draws our attention to three theories (deficit, dominance, difference) that emphasize the distinction between men and women in their use of language. He mentions that deficit theory points to the role of culture in constructing the female identity by restricting females' use of language to what they call a 'Lady like' language. Baxter (2011) mentions that dominance theory has two branches: (i) language as a social interaction which highlights the inequality between genders through daily interactions, and (ii) language as a system that looks at sexism within a language. Baxter argues that difference theory indicates the different conventional goals of men and women interactions, while men tend to perform a language of competition effect, women use a language of equality and trust.

It is significant to note that diversity may be intergender (between genders), or intragender (exists within each gender), the latter may be due to other factors such as age, social class, ethnicity, family background, and education (Norton and Pavlenko, 2004, as cited in Baxter, 2011).

\subsection{Related Studies}

Numerous studies have attempted to shed the light on greeting rituals in some communities and tried to investigate gender differences in greeting behavior. Al-Shehri (2008) examines greeting behavior among Saudi students in the United States. He finds that the Arabic greeting expression 'As-salaamu 'alaykum' is the most frequent greeting expression, then comes 'Marhaba.' He also concludes that males and females greet people differently, females spent much time than men in greeting other females. Moreover, he notes that males and females tend to use Modern Standard Arabic when they greet people with different Saudi dialects.

Almegren (2017) compares the greeting speech act of Arabic Saudi speakers and English American speakers. She concludes that there are many factors, such as cultural differences, social status, and setting and situation, affect Saudis and Americans decision making regarding their speech act. However, Americans are less likely to consider social and physical distance than Saudis.

In different context, Gharaghani, Rasekh, Dabaghi, Tohidianb (2011) investigate the effect of gender on politeness strategies in greeting behavior of EFL Iranian students. Their study deals with the students' ability to employ politeness strategies when using their native Persian and EFL, furthermore, they examine the role of the greeters' gender on their choice of politeness strategies. They find that the degree of formality increases in different gender greeting. Moreover, they argue that females tend to use more power-politeness strategies in greeting both genders more than males. However, females were more formal than males in their greeting behavior.

\section{Method}

This research is a mixed method study that adopts both qualitative and quantitative methods. It seeks information about greeting behavior among male and female Saudi adults according to the addressee's identity. It also 
investigates the reason behind the use of each greeting behavior. In the first part of the study, qualitative data are collected through observations of Saudi society, focusing on how males and females perform their greeting rituals, what are their verbal and nonverbal greeting customs. In light of the collected data from the observations, the second part of the study, which is descriptive in nature, built its instrument, to compare the data collected from both methods to come with reliable results. The instrument employed to collect quantitative data is a questionnaire that elicited males and females' greeting behavior towards their grandparents, parents, siblings, and friends, and their perspectives toward these behaviors.

\subsection{Participants}

The participants of the study are Saudis who were born and raised in Saudi Arabia. 72 Saudi citizens from different regions of Saudi Arabia participated in the study, 22 males and 50 females (there was a difficulty in contacting male participants which explains the unequal proportions of participants between males and females). All the participants are adults whose ages are above 18 years. The study adopted simple random sampling which is according to Mackey (2005) is considered the best sampling procedure because of its representativeness of the targeted population. The random sampling is employed to elicit information about Saudi greeting behavior in general without being restricted to a specific family or region (as the participants are from different regions of Saudi Arabia).

\subsection{Instruments}

The study adopted both qualitative and quantitative methods. Data were collected qualitatively by means of observations and quantitatively by means of questionnaires.

\subsubsection{The Observations}

Observations of Saudi society took place in different settings in order to identify the verbal and nonverbal greeting behavior of male and female Saudi adults. The first setting focuses on the greeting rituals among family members how gather weekly. The second setting focuses on the greeting rituals of people who meet their grandparents. The third setting focuses on the greeting rituals among friends who meet in school, coffee shops etc. Taking note is used to document greeting behavior in each setting.

\subsubsection{The Questionnaire}

The questionnaire was designed according to the data collected in the observations to identify to what extent the data collected in the observations reflect similar results from the questionnaire. The questionnaire has two parts. The first part is concerned with the nonverbal greeting behaviors and the reasons behind using these greeting behaviors. The second part of the questionnaire is an open space which is concerned with the verbal greeting expressions Saudis use when they meet their grandparents, parents, siblings, and friends, and the reasons behind using such expressions (see Appendix A).

The questionnaire was designed with the use of Google Forms in order to facilitate data collection. Two forms of the questionnaire were designed, one is concerned with male participants and the other is concerned with female participants, in order to facilitate data collection and analysis. However, both forms have the same sections and questions.

\section{Results}

After collecting data by both qualitative and quantitative techniques, the data where analyzed and interpreted qualitatively and quantitatively. The following sections will represent the results obtained from data analysis.

\subsection{Observation Results}

As mentioned earlier, the observations happened in three settings: family gathering, visiting grandparents, and meeting friends. Each theme has its own features that will be presented with regard to gender differences.

\subsubsection{Family Gathering}

In this setting, Saudi people meet their parents and siblings. They, both males and females, usually shake their parents hands and kiss their forehead and say 'Aslam alaikum,' 'Hala wa Allah, then they ask 'Wesh lounik,' 'Kaif alhal'(how are you?). Another less frequent behavior is that they kiss their parents' hand as well. Moreover, when greeting their siblings, males usually shake their brothers and sisters' hands, females on the other hand, usually shake their brothers' hand, but when they greet their sisters, they shake hands and kiss on the cheeks. Both males and females use similar greeting expressions when they greet their siblings saying: 'Hala wa Allah,' 'Shlounk,' and 'Wesh akbark.' 


\subsubsection{Visiting Grandparents}

In this setting, males and females perform similar greeting behavior when they greet their grandparents. They both kiss their grandparents' forehead and frequently kiss their hands. For the verbal greeting expression, they usually say 'Hala wa Allah,' 'Shlounk,' 'Wesh akbarik,' and 'Basher an sehatik.'

\subsubsection{Meeting Friends}

Males and females differ in their way of greeting their friends. Females usually shake hands delicately, kiss on the cheeks, and hug their friends. They greet their friends by saying 'Kaifik' Hala wa Allah,' 'Shlounk,' and 'Wesh akbarik'. Males, on the other hands, usually shake hands firmly and rarely kiss on the cheeks. They use more masculine expressions when greeting their friends, like saying: 'Arhib' 'Hala wa Allah' 'Akbar aloum'.

\subsection{Questionnaire Results}

After data collection, the researcher organized the data and analyzed the responses of the participants in order to answer the research questions. However, since the second research question (the reasons behind each greeting behavior) is closely related to the first question, the results related to that question will be included in the results of the first question. In this way, the results will be more comprehensive, so, that each greeting behavior is immediately related to its explanation.

Table 1. Females Nonverbal Greeting Behaviors

\begin{tabular}{ccccccc}
\hline & $\begin{array}{c}\text { Shaking } \\
\text { hands }\end{array}$ & $\begin{array}{c}\text { Shaking and } \\
\text { kissing on the } \\
\text { cheeks }\end{array}$ & $\begin{array}{c}\text { Kissing } \\
\text { forehead }\end{array}$ & $\begin{array}{c}\text { Kissing } \\
\text { hand }\end{array}$ & $\begin{array}{c}\text { Hugging and } \\
\text { Kissing }\end{array}$ & Other \\
\hline Mother & $8 \%$ & $16 \%$ & $26 \%$ & $2 \%$ & $30 \%$ & $18 \%$ \\
Father & $4 \%$ & $20 \%$ & $38 \%$ & $4 \%$ & $12 \%$ & $22 \%$ \\
Grandmother & $4 \%$ & $20 \%$ & $38 \%$ & $2 \%$ & $14 \%$ & $22 \%$ \\
Grandfather & $6 \%$ & $12 \%$ & $42 \%$ & $4 \%$ & $0 \%$ & $36 \%$ \\
Sister & $10 \%$ & $34 \%$ & $0 \%$ & $0 \%$ & $42 \%$ & $14 \%$ \\
Brother & $34 \%$ & $38 \%$ & $2 \%$ & $0 \%$ & $8 \%$ & $18 \%$ \\
Friend & $16 \%$ & $28 \%$ & $0 \%$ & $0 \%$ & $48 \%$ & $8 \%$
\end{tabular}

The results obtained from the preliminary analysis of females' responses reveal that Saudi females greet their relatives (grandparents, parents, siblings) and friends differently. $30 \%$ of the females mentioned that they hug and kiss their mothers when they greet them to show love and respect. $26 \%$ of the female participants mentioned that they kiss their mothers' forehead when greeting them, they argued it is the tradition and to show respect. $18 \%$ of the female participants responded to the option OTHER arguing that they use a combination of these behaviors such as kissing forehead and hand or kissing forehead and cheeks to show love as well as respect and appreciation. The least performed behavior by Saudi females is shaking hand when greeting their mothers, some mentioned because 'I used to do this,' others mentioned that because they are not in a good relationship with their mothers. Verbally, many of the females use the expression 'Aslam alaikoum' when they meet their mothers. The second frequent greeting expression used by females is 'Hala wa gala' and 'Hala wa Allah'. Following this, some female participants, prefer to accompany their greeting expression with the utterance of 'mom,' or 'mommy' like saying 'Hala youmah' (hello mom) and 'B'alkair youmah' (With welfare mom).

As can be seen from Table 1 above, females greet their fathers similarly as they greet their mothers. $38 \%$ of the female participants mentioned that they kiss their fathers' forehead when greeting them saying that this behavior shows respect and appreciation, love, and it is a suitable way of greeting. Some females, only $20 \%$, reported that 
when greeting their fathers, they shake hands and kiss on cheeks because this behavior shows respect and appreciation, love, and because it is a tradition. Another proportion (22\%) responded to the option OTHER, some of them reported that they perform a combination of these behaviors like shake hands, kissing cheeks, and forehead or kissing forehead and hand to show respect, few mentioned that they perform only verbal greeting because they are not in a good relation or because they used to do it this way, other reported that they lost their fathers. The least nonverbal greeting behavior performed by females when greeting their fathers was shaking hands, with only $4 \%$ of the responses, saying that they do this because it is the suitable way of greeting or to show love. Regarding verbal greeting, females generally use 'Aslam alaikum' when greeting their fathers. They use other expressions like 'Hala wa gala' and 'Hala wa Allah,' they also mentioned that they use the utterance 'Yubah /Abouy' (dad) alongside the greeting expression.

Moreover, the data in Table1 show that $38 \%$ of the female participants kiss their grandmothers' forehead when greeting her, they reported that it is a traditional practice and it shows respect and appreciation. Some female participants, only $20 \%$, mentioned that they shake hands and kiss on the cheeks when greeting their grandmothers, some of them said that they do so to show respect and appreciation and love, others mentioned it is tradition, some simply said 'because she is my grandmother.' Another proportion (22\%) reported that some of them use a combination of nonverbal behaviors like shaking hands, kissing on cheeks and forehead, and hug their grandmothers to show respect, appreciation, and love, other mentioned that they kiss their forehead and hand to show respect and appreciation, some reported that they lost their grandmothers. Moreover, $14 \%$ of the females mentioned that they hug and kiss their grandmothers to show respect and love, whereas others explain that they do so because they used to. The least frequent nonverbal greeting behaviors are kissing hands and shaking hand, with $2 \%$ and $4 \%$ respectively. On the other hand, verbal greeting, generally, has three features. The first feature is the frequent use of the greeting expression 'Aslam alaikoum,' 'Hala wa Allah,' and 'Hala wa gala.' The second feature is mentioning the expression 'Youh' (a traditional and old-fashioned version of mom), 'Youmah $\backslash$ Ummy' (mom), and 'Jadaty' (grandmother) alongside the greeting expressions. The third feature is that performing some prayers in the greeting expressions such as 'Allah yataool b'omrik' (May Allah grant you with long life).

Greeting grand fathers is quite similar to greeting grandmothers verbally and nonverbally as Table 1 suggests. $42 \%$ of the females responded to kissing forehead as their usual greeting behavior to their grandfathers, they argued that this practice shows respect and appreciation as well as love, they also think it is a traditional practice, further, some mentioned because they are old. Another proportion, of $36 \%$, responded to the option OTHER, some of them mentioned that they lost their grandfather, others reported that they use a combination of the suggested greeting behaviors like kissing forehead and hand as well as hugging to show respect, appreciation, and love. Few females, only $12 \%$ reported that they shake hands and kiss on cheeks mentioning that they use this behavior to show respect and appreciation, because they 'used to do' so, and because 'he likes it this way.' The least performed greeting behaviors are Kissing hand and Shaking hand, with only $4 \%$ and $6 \%$ of the responses respectively, whereas Hugging and kissing received no response. However, verbal greeting takes three forms: females frequently use the greeting expressions 'Aslam alaikoum' and 'Hala wa Allah' 'Hala wa gala,' employing the expressions 'Yubah' and 'Jaddy' with the greeting expressions, and using some prayers to greet like 'Allah yataool b'omrik' (May Allah grant you with long life).

In contrast, greeting sisters is different from greeting parents and grandparents. A great percentage of the responses, $42 \%$, were to Hugging and kissing, the respondants argued that they perform such behavior because it is a ritual and it is considered a less formal behavior, some reported that they do so because they are their sisters and they love them. The second frequent greeting behavior is Shaking hands and kissing on the cheeks, $34 \%$ of the responses, females argued that it shows love and is considered as a traditional practice. Some female participants, only $14 \%$, responded to the option OTHER, some of them mentioned that they don't have sisters, an interesting response is that some of them argued they don't greet each other, another interesting response is that if their sister is older than them, they may kiss their forehead. Only $10 \%$ of the females mentioned that they shake hands with their sisters when greeting them arguing that because they are their sisters and 'always with me.' However, the options Kissing forehead and Kissing hand received no responses as Table 1 illustrates. Moreover, although the majority of the females tend to use classical greeting expressions like 'Aslam alaikoum,' 'Hala wa gala,' and 'Hala wa Allah,' some of them tend to use less formal and special greeting expressions like 'Hala b'roohi' (Hi my soul) or using some foreign language greeting expressions. The use of the expression 'Okti' (my sister) alongside greeting expressions is also frequent.

Interestingly, greeting brothers takes different form than greeting sisters. A great percentage of the responses (38\%) were to Shake hands and kiss on cheeks, the respondents mentioned that this behavior shows love, respect, 
and it is a traditional ritual. More than one third of the females (34\%) shake hands when greeting their brothers, they argued that this act is a tradition and more formal as well as it shows respect, other mentioned that they do so 'because he is my brother' or as a sign of respect. $18 \%$ of the female participants responded to the option OTHER, they reported that they perform only oral greeting with their brothers, some of them indicated that it depends on the age of their brother. Only a few proportion (8\%) reported that they hug and kiss their brothers, arguing that is because he starts it, he is my support, and it is less formal. It is worth noting that kissing forehead received only $2 \%$ of the responses and kissing hand received no responses at all. Verbally, the majority of the female participants tend to use expressions such as 'Aslam alaikum,' 'Hala wa Allah,' 'Hala wa gala,' and 'Marhaba/ Hala.' However, only few reported that they use the expression 'Akoi' and 'Akayee' (my brother) when greeting their brothers. Similarly, few prefer to mention the name or epithet of their brothers with the greeting expression like saying 'Hala Ahmed' (Hi Ahmed) or 'Hala Abo Abdullah' (Hi the father of Abdullah). An interesting response reveals that 'it is different from one brother to the other.'

On the other hand, females relatively greet their friends as they greet their sisters. Almost half of the female participants, $48 \%$ of the females, responded that they hug and kiss their friends when meeting them, they argued that this act is a reflection of love, appreciation, and yearning, some mentioned it is less formal and it is a ritual practice. $28 \%$ of the responses were to Shaking and kissing on the cheeks, they say that it is a ritual and it shows respect and appreciation, other mentioned because 'she is my friend.' Few responses (16\%) were to Shaking hands, the respondents argued that this is the best way to greet a friend, others mentioned because 'she is just a friend,' some simply say 'I don't know why.' Only $8 \%$ responded to the option OTHER mentioning that their greeting depends on the situation or they only perform oral greeting. Interestingly, the options Kissing forehead and Kissing hand received no responses as Table 1 shows. Verbal greeting may take less formal form. Only few female participants reported that they say 'Aslam alaikum,' whereas the majority mentioned that they say 'I miss you,' 'Hala,' and 'Ahlain.' Someone mentioned that it depends on the type of relation (close friend or just a friend).

Table 2. Male Nonverbal Greeting Behaviors

\begin{tabular}{|c|c|c|c|c|c|c|}
\hline & $\begin{array}{l}\text { Shaking } \\
\text { hands }\end{array}$ & $\begin{array}{l}\text { Shaking and } \\
\text { kissing on the } \\
\text { cheeks }\end{array}$ & $\begin{array}{l}\text { Kissing } \\
\text { forehead }\end{array}$ & $\begin{array}{l}\text { Kissing } \\
\text { hand }\end{array}$ & $\begin{array}{l}\text { Hugging and } \\
\text { Kissing }\end{array}$ & Other \\
\hline Mother & 0 & 9.1 & 13.6 & $50 \%$ & 9.1 & $18 \%$ \\
\hline Father & 0 & $18.2 \%$ & $13.6 \%$ & $54.5 \%$ & 0 & $13.6 \%$ \\
\hline Grandmother & $4.5 \%$ & $9.1 \%$ & $22.7 \%$ & $45.5 \%$ & 4.5 & $13.5 \%$ \\
\hline Grandfather & $4.5 \%$ & $9.1 \%$ & $9.1 \%$ & $50 \%$ & $4.5 \%$ & $22.5 \%$ \\
\hline Sister & $68.2 \%$ & $18.2 \%$ & $4.5 \%$ & $4.5 \%$ & $4.5 \%$ & 0 \\
\hline Brother & $63.6 \%$ & $18.2 \%$ & $13.6 \%$ & 0 & 0 & $4.5 \%$ \\
\hline Friend & $40.9 \%$ & $45.5 \%$ & 0 & 0 & $9.1 \%$ & $4.5 \%$ \\
\hline
\end{tabular}

The other group of the participants is the male group, and as female, they greet their relatives and friends distinctively as it appears in Table 2 . When greeting their mothers, half of the participants, specifically $50 \%$ of the males, reported that they kiss their mothers' hand to show respect and appreciation. $18 \%$ of the males responded to the option OTHER mentioning that they kiss the forehead and hands of their mothers reporting that this act shows respect and appreciation as well as it is considered a traditional practice. A small proportion, of $13,6 \%$, mentioned that they kiss their mothers' forehead as a greeting behavior, they argued it is a sign of appreciation. The least two greeting acts performed by male participants when greeting their mothers are Shaking and kissing on the cheeks and Hugging and kissing. Those who responded mentioned that these behaviors show 
appreciation and love respectively. Verbal greeting takes different forms, some preferred to use 'Aslam alaikum' and 'Hala wa Allah.' Some of the male participants tended to mention that they are precious like saying 'Hala b'Algaliah' (Hello precious) whereas others prefer to say 'Allah hayha' (May Allah greet you).

In the same vein, a great proportion of male participants (54\%) mentioned that they kiss their fathers' hand when greeting them arguing that by this act they show respect and appreciation. $18.2 \%$ of the males reported that they shake hands and kiss on the cheeks, they perform this as a traditional practice and it shows respect and appreciation. Kissing the forehead received $13.6 \%$ of the responses, the respondents reported that it shows appreciation and his status. A similar proportion, of $13.6 \%$, responded to the option OTHER, some reported that they kiss the forehead and hand of their father mentioning it is a tradition, others mentioned that they lost their fathers. It is worth mentioning that the options Shaking hands and Hugging and kissing received no responses. Verbally, the majority tended to use 'Aslam alaikum' and 'Hala wa Allahlgala.' Some mentioned the use of 'Allah hayah' (May Allah greet you) as a preferred greeting expression.

Moreover, greeting grandmothers take various forms. Almost half of the males, $45.5 \%$ of the responses, reported that they kiss their grand mothers' hand as a greeting behavior mentioning that it is a sign of respect and appreciation. $22.7 \%$ of the males responded to Kissing forehead as a greeting act because it shows respect and appreciation as well. $13.5 \%$ of the male participants reported that they lost their grandmothers. A small proportion $(9.1 \%)$ of the participants shake hand and kiss on the cheeks as a greeting behavior saying that they show respect by such act. Shaking hand and Hugging and kissing options were the least performed greeting behaviors with only $4.5 \%$ for each. The frequent verbal greeting expression is 'Aslam alaikum.' Some reported that they say 'Hala ya yummah' (Hello my Mam) whereas others employ prayers as a greeting expression such as 'Allah yataool bi omrik' (May Allah grant you with long life).

Greeting grandfathers is relatively similar to greeting grandmothers. Half of the male participants reported that they kiss their grandfathers' hand to show respect and appreciation. $22.5 \%$ of the males' responses were to the option OTHER mentioning they lost their grandfathers. Similar proportions of the responses, of $9.1 \%$ for each, were to the options Shaking hands and Kissing on cheeks and Kissing forehead, the participants argued that these acts show respect and appreciation and the latter is considered traditional acts. The least greeting behaviors performed by males when greeting their grandfathers are Shaking hands and Hugging and kissing. Regularly, males use the expression 'Aslam alaikum' as a verbal greeting. Other reported verbal greeting expressions are 'Hala yubah' (Hello dad) and 'Allah yataool bi omrik' (May Allah grant you with long life), they employ prayers as greeting expressions.

Greeting sisters is completely different from greeting grandparents. The vast majority of the male participants greet their sisters by shaking hands with a proportion of $68.2 \%$, they argued that they perform such behavior because it is a traditional practice, other mentioned because they meet regularly. Shaking and Kissing on the cheeks is the second preferred greeting behavior with $18.2 \%$ of the responses, respondents mentioned they act this way because it shows respect and appreciation and because they are in the same social status. The other three greeting behaviors received the same percentage of responses $(4.5 \%)$, respondents argued that they do so because 'she is older,' it shows respect and appreciation, and because 'she is my only sister.' Many of the males use verbal expressions like 'Hala' and 'Ahleen' when greeting their sister. A similar number mentioned they prefer 'Aslam alaikum' as a greeting expression. Few reported that they use 'Okti' (my sister) or use her epithet like 'Um Muhammed' (the mother of Muhammed) alongside the greeting expression.

Greeting brothers is relatively similar to greeting sisters. More than half of the males (63.6\%) reported that they shake hands when greeting their brothers arguing that it is a traditional practice, other mentioned because they meet regularly. The second frequent greeting behavior is Shaking hands and Kissing on the cheeks mentioning that such an act is a traditional practice and because they are in the same social status. $13.6 \%$ of the male participants reported that they kiss their brothers' forehead because 'he is a child' and because 'I am proud of him.' An interesting finding is that the options Kissing hands and Hugging and kissing received no responses whereas only $4.5 \%$ reported that they have no brother. Verbally, the majority tend to use 'Aslam alaikum' and 'Hala wa Allah' and 'Hala b'ik' as greeting expressions. Few mentioned that they use 'Marhaba' and 'Arheb' when greeting brothers. Some reported they employ the expression 'Akoi' or the epithet alongside the greeting expression like 'Hala akoi' (Hello brother) 'Abo Muhammed' (the father of Muhammed).

On the other hand, greeting friends is slightly different than greeting brothers. $45.5 \%$ of the males greet their friends by shaking hands and kissing on cheeks arguing that such behavior is a traditional practice or because they meet after a period of time. A slightly similar proportion, of $40.9 \%$, mentioned that they only shake hands because 'he is a friend,' they meet regularly, or it is a traditional practice. Surprisingly, $9.1 \%$ reported that they 
hug and kiss their friends because 'I love him' or to show appreciation. Interestingly, no responses were placed to kissing forehead or kissing hand as a greeting behavior whereas only $4.5 \%$ mentioned that they use casual facial expression as a greeting behavior. Moreover, the majority preferred 'Aslam alaikum' as a verbal greeting expression. Some reported the use of 'Hala' 'Ahlain 'Arheb' as their greeting expressions. Few mentioned the use of epithet 'Abo Abdullah' alongside the greeting expression when greeting their friends. Interestingly, few mentioned the use of other dialects in their greeting expression such as 'Marhaba e'sai' which is an Emirati greeting expressing.

There are some major differences as well as minor similarities between Saudi males and females in their greeting behavior. Males and females are different in the way they greet their parents. Males tend to kiss their parents' hands as the most frequent reported greeting behavior. Females prefer hugging and kissing when greeting their mothers whereas they tend to kiss forehead, shake hands, and kissing on the cheeks when greeting their fathers. When greeting grandparents, males prefer to kiss their grandparents' hand whereas females prefer to kiss the forehead, shaking hands, and kissing on the cheeks. When greeting their siblings, males tend to use a unified greeting behavior for both, sisters and brothers, whereas females tend to differentiate between greeting sisters from brothers, Hugging and kissing and Shaking hands and kissing on cheeks, respectively. Moreover, when greeting their friends, males shake hands and kiss on cheeks whereas females prefer hugging and kissing as greeting behaviors. In regard to verbal expressions, although both genders tend to greet their parents and grandparents similarly, they differ in the verbal way they greet their siblings and friends.

\section{Discussion}

After scrutinizing the data, it is obvious that Saudi males and females accommodate their greeting behavior according to the addressee. This strongly supports the concept of the audience design as speakers "are paying attention to who they are addressing" (Meyerhoff, 2006, p. 29). As the findings suggest, males tend to greet their parents and grandparents in the same way by kissing their hands. That suggests males don't differentiate the way they greet highly ranked family members. The use of hand kissing reflects their respect and appreciation to them. In contrast, greeting siblings takes different forms from that of parents and grandparents. Males tend to greet their siblings by shaking hand which indicates that males greet those who share similar rank in the family in a more traditional way. Similarly, greeting friends can be in a more traditional way (shaking hands) especially if they meet regularly, but if they meet after a long period of time, they shake hands and kiss on the cheeks. Greeting siblings and friends directly corresponds to the findings obtained in the observations.

On the other hand, females tend to be diverse in the way they greet their relatives and friends. When greeting their mothers, some tend to show respect and appreciation by kissing their forehead and hand, others tend to show love and warm-heartedness by hugging and kissing them, further some tend to show both feelings by performing all of these behaviors. This diversity could be explained in the light of the nature of the relation between mother and daughter whether they are close to each other or there is a distance between them. In contrast, greeting fathers and grandfathers is mainly restricted to the feeling of respect and appreciation (kissing forehead and hands), this is due to the formal father-daughter relation in the Saudi society, it also reflects the social constraint between male and female in the Saudi society. This corresponds to Gharaghani et al. (2011) conclusion that formality increases in intergender greeting situations. Greeting grandmothers generally reflects respect and appreciation by kissing forehead and kissing on the cheeks. This slightly corresponds to the findings obtained through observations. In general, this is a traditional practice perform in such greeting situation. When greeting siblings, gender plays a role here. Females differentiate between greeting sisters and brothers, that is associated with the intergender differences in performing speech act as suggested by Norton and Pavlenko (2004 as cited in Baxter, 2011). They tend to show love and warm-heartedness to their sisters by hugging and kissing them, whereas they tend to show respect to their brothers by using traditional way of greeting like shaking hands and kissing on cheeks. Interestingly, that largely corresponds to the males' way of greeting with their sisters, as they reported, and reinforces the social constraint between male and female in Saudi society. Moreover, this somehow corresponds to the data obtained through the observations regarding sisters and brothers greeting behavior. Greeting friends is similar to greeting sisters in showing love and yearning by hugging and kissing them. However, social distance may play a role here as some reported that the way they greet their friends depends on the degree of their friendship. This finding confirms the association between greeting as a speech act and factors such as social status and settings as suggested by Almegren (2017).

Regarding the verbal greeting, in both genders greeting expressions 'Aslam alaikum' is the most frequent expression used to greet all types of addressee. This finding is in agreement with Al-Sheheri's (2008) findings which show that 'As-salaamu 'alaykum' is the most frequent greeting expression among Saudis. However, there are minor differences in the greeting expressions with regard to the addressee. Both gender use more formal 
expressions like 'Aslam alaikum' and 'Hala wa Allah' when greeting parents and grandparents. Subsequently, this formality declines as we move lower in rank like with siblings, using expressions like 'Marhaba, 'Hala,' and 'Ahlain,' again this finding is in consistence with the findings of Gharaghani et al. (2011). Although males and females greet their friends relatively as they greet their siblings, males tend to be more formal with friends than female, moreover, male tend to use their addressees' epithet (mainly siblings and friends) alongside the greeting expression whereas some of the female participants reported such employment when greeting brothers. Surprisingly, the idea that males are more formal in their greeting is in contrast to the finding of Gharaghani et al. (2011) which suggests that females tend to be more formal than male in their greeting.

\section{Conclusion and Implications}

Greeting behavior is a significant social act as it is considered the initiative act of any interactions. Different studies have investigated greeting behavior of Saudi speakers (Almegren, 2017; Al-Sheheri, 2008), however, few studies investigated greeting behavior in the Saudi context. Moreover, few studies have considered the role of the addressee in the way people greet each other. This study aims at studying the greeting behavior in the Saudi context in regard to the effect of the addressee on the greeting behavior and the gender of the greeter.

The findings of the study show that males and females accommodate their greeting behavior according to their addressee. The formality of the greeting behavior depends on the social (familial) status and social distance between the greeter and addressee. Moreover, verbal greeting expressions of both genders vary in regard to the addressee. However, males and females mainly differ in their nonverbal greeting behavior, whereas males seem to be more consistent in their greeting behavior specially between similar social rank relatives, females tend to be more diverse in their greeting behavior. Although the current study is based on a small sample of participants, the findings suggest that the addressee plays a significant role in both genders' greeting behavior.

The current findings add to a growing body of literature on the Saudi greeting behavior in particular and greeting as a speech act in general. The analysis of male and female greeting behavior with regard to the addressee undertaken here has extended our knowledge of the Saudi rituals of greetings, the social constraint imposed on Saudi males and females, and the role of the familial rank on the greeting behavior. This research will serve as a base for future studies and investigations on the greeting behavior, especially in the Saudi context.

Although this study makes a major contribution to research on sociolinguistics in particular and applied linguistics in general by demonstrating the dimensions and features of greeting in the Saudi context, this study may have some limitations. The number of the male participants was relatively not representative enough comparing it with female participants. This was due to the difficulty to contact Saudi males. Some of the participants reported the lack of social relations because they don't have siblings or they lost their relatives, this has affected the description of the data. Moreover, interviews would be more effective to elicit information from the participants as some of them provide responses that does not make sense to the study, so, clarification and negotiation of interview would be significant.

This research has thrown up many questions in need of further investigation. Since greeting rituals diverse between family members and friends, other studies may investigate greeting behavior in other social settings like in the workplace, between professionals, students and teachers and etc. Further research is needed to account for the varying features of the verbal greeting expressions expressed by Saudis.

In conclusion, to establish an effective interaction initiated with the appropriate greeting behavior in the Saudi context, consider the following practical implications:

1. Kissing forehead and hand show respect and appreciation that is used with highly ranked family members.

2. Shaking hand and kissing on cheeks is a traditional way of greeting practiced with similar ranked family members.

3. Hugging and kissing are a less formal greeting behavior practiced mainly by female or to female.

4. There is a social constraint between males and females in their greeting behavior which should be considered.

5. Males tend to be more formal with their friends than females.

6. Males tend to use their addressees' epithet alongside the greeting expression more than females. 


\section{References}

Almegren, R. (2017). Speech act of greeting for American native speakers of English and Saudi native speakers of Arabic: A comparative study. International Journal of Applied linguistics \& English Literature, 6(7), 243-260. http://dx.doi.org/10.7575/aiac.ijalel.v.6n.7p.243

Al-Shehri, A. (2008). Gender differences in the greeting rituals of the Saudis in America. The Journal of Education College, 19(77), 1-19.

Austin, J. L. (1962). How to do things with words. In J. O. Urmson (Ed.), The William James Lectures delivered at Harvard University (pp. 1-163). The Clarendon Press.

Baxter, J. (2011). Gender. In J. Simpson (Ed.), The Routledge handbook of applied linguistics (pp. 331-343). New York, NY: Routledge.

Gharaghani, Z., Rasekh, A. E., Dabaghi, A., \& Tohidian, I. (2011). Effect of gender on politeness strategies in greetings of native speakers of Persian; English and EFL learners. Cypriot Journal of Educational Science, 3(2011), 93-117.

Gulida, V. (2010). Sociolinguistics in the Russian Federation, Ukraine, Belarus and Moldova. In M. J. Ball (Ed.), The Routledge handbook of sociolinguistics around the world (pp. 385-401). New York, NY: Routledge.

Holems, J. (2013). An introduction to sociolinguistics ( $4^{\text {th }}$ ed.). New York, NY: Routledge.

Lakoff, R. (1973). Language and woman's place. Language in Society, 2, 45-80.

Mackey, A., \& Gass, S. M. (2005). Second language research: Methodology and design. Mahwah, New Jersey: Lawrence Erlbaum Associates.

Medina, J., Dávila, Y., Romero, V., \& Mora, E. (2018). The Venezuelan greeting. A multiform ritual of visual prosody. Lengua Y Habla, (22), 1-24.

Meyerhoff, M. (2006). Introducing sociolinguistics. New York, NY: Routledge.

Wardhaugh, R. (2006). An introduction to sociolinguistics ( $5^{\text {th }}$ ed.). Blackwell Publishing Ltd.

Yoosefvand, A., \& Rasekh, A. E. (2014). Gender differences in the expression of gratitude by Persian speakers. Journal of Applied Linguistics and Language Research, 1(1), 100-117. 


\section{Appendix A}

Questionnaire Form

\begin{tabular}{c|c|c|c|c|c|c|c}
$\begin{array}{c}\text { Greeting } \\
\text { behavior } \\
\begin{array}{c}\text { I usually } \\
\text { greet my .....by }\end{array}\end{array}$ & $\begin{array}{c}\text { Shaking } \\
\text { hands }\end{array}$ & $\begin{array}{c}\text { Shaking and } \\
\text { kissing on } \\
\text { the cheeks }\end{array}$ & $\begin{array}{c}\text { Kissing } \\
\text { forehead }\end{array}$ & $\begin{array}{c}\text { Kissing } \\
\text { hand }\end{array}$ & $\begin{array}{c}\text { Hugging } \\
\text { and Kissing }\end{array}$ & Other & Why? \\
\hline
\end{tabular}

Mother

Father

Grandmother

Grandfather

Sister

Brother

Friend

What are the greeting expressions that you use when you greet the following people (do say Salam Alaikum Marhaba - Hala wa Gala - Hal wa Allah - Kaif Alhal - Shloun' ik etc.)? Please mention why do you use each expression? Feel free to write in your own dialect.

Mother

Father

Grandmother

Grandfather

Sister

Brother

Friend

\section{Copyrights}

Copyright for this article is retained by the author(s), with first publication rights granted to the journal.

This is an open-access article distributed under the terms and conditions of the Creative Commons Attribution license (http://creativecommons.org/licenses/by/4.0/). 